\title{
Journal of Contemporary European Research
}

Volume 16, Issue 1 (2020)

Research Article

\section{Using Policy Briefs as Assessment to Integrating Research-Led Employability in Foreign Policy Courses}

\section{Simon Lightfoot}

\section{Citation}

Lightfoot, S. (2020). 'Using Policy Briefs as Assessment to Integrating Research-Led Employability in Foreign Policy Courses', Journal of Contemporary European Research 16(1):25-36.

https://doi.org/10.30950/jcer.v16i1.1083 


\section{Abstract}

The aims of this paper are to highlight the way policy briefs were employed as an assessment tool on a final year foreign policy orientated Politics/IR module in a UK university. It explores the skill/employability rationale behind the use of the tool alongside wider concerns about diversity of assessment before moving onto some practical aspects of its introduction within the module and the evolution of the task. Finally, it reflects on student opinion of the assessment, it highlights some of the expected and unexpected challenges in using policy briefs as an assessment tool and proposes some future modifications. Overall, this paper argues that policy briefs can be utilised on more "traditional" modules and that they have a range of benefits for both students and staff, confirming the general findings of Chagas-Bastos and Burges (2018) and others, whilst making a more explicit case for their use in relation to the fact that the tool allows students to demonstrate research-based employability skills.

\section{Keywords}

Policy brief; Assessment; Employability; Research-led teaching

\section{INTRODUCTION}

There is a long- standing debate within higher education about the extent to which assessment tasks should mirror tasks students will encounter when they enter the workplace. There is a focus on ensuring assessment tasks are "authentic" i.e. they "replicate the tasks and performance standards typically found in the world of work' (Villarroel et a 2018) thereby 'requiring students to use the same competencies, or combinations of knowledge, skills, and attitudes that they need to apply in the criterion situation in professional life' (Gulikers, Bastiaens, and Kirschner 2004: 69). Aside from the preparation for work, Villarroel et al's study highlighted that authentic assessment has been found to have a positive impact on student learning, autonomy, motivation, self-regulation and metacognition; abilities highly related to employability, whilst Lincoln and Casidy (2018) found that authentic assessments were positively related to student satisfaction and promoting behaviour.

Despite these perceived benefits, the use of 'authentic assessment' in politics and IR remains niche. In part that is because politics and IR lack a specific work task to replicate that might be found in say nursing or even environmental studies. The range of authentic assessment tasks in Politics/IR ranges simulations to portfolio submissions (Blair 2015) but the focus of this paper is to explore the issues around the use of policy brief or briefing notes as assessment tasks. These tasks have been utilised on placement modules/internships but there take up remains low. In 2009 Boys and Keating argued that 'international relations and political science curricula in the UK would benefit from the wider use of this tool [policy briefs]' and yet more recent research suggests policy briefings are still an 'underutilized pedagogical tool' (Chagas-Bastos and Burges 2018). In the UK, it was found that policy brief writing was evident in only $2.3 \%$ of Russell Group modules and $1.4 \%$ of Non-Russell Group modules 
(Clark and Martin 2016). Chagas-Bastos and Burges (2018) suggest the syllabi sampled in the US, Canada, Australia, Brazil, and Colombia show similar usage rates.

The aims of this paper are to highlight the way policy briefs were employed as an assessment tool on a final year module in a research-intensive UK university-the University of Leeds. It explores the skill/employability rationale behind the use of the tool alongside wider concerns about diversity of assessment before moving onto some practical aspects of its introduction within the module and the evolution of the task. Finally, it reflects on student opinion of the assessment, it highlights some of the expected and unexpected challenges in using policy briefs as an assessment tool and proposes some future modifications. Overall, this paper argues that policy briefs can be utilised on more "traditional" modules and that they have a range of benefits for both students and staff, confirming the general findings of Chagas-Bastos and Burges (2018) and others, whilst making a more explicit case for their use in relation to the fact that the tool allows students to demonstrate research-based employability skills.

\section{Context}

UK universities increasingly focus on the employability agenda as does the EU's Bologna process (Niemann and Heister 2011). One aspect of this is to ensure students are aware of and able to employ the skills they develop as part of their university education in future employment. Given that political science and IR are 'diverse disciplines' that do not 'train students for a certain profession' means that 'students often feel uncertain of the career paths available to them and how their expertise can be used in a future career' (Broms and Licht 2019). There is also a feeling that political science/IR degrees do not provide students with the skills requested by employers-what can be called the workplace relevance of a BA (Robinson 2013; Biswas and Haufler 2018). There is therefore a need to more explicitly link student and employer expectations along with governance pressures in this field to respond to this agenda without damaging academic standards. One solution is to ensure that the employability agenda is 'embedded into the curriculum' (Maurer and Mawdsley 2013).

Research from the UK (Lee et al 2014) and the US (Biswas \& Haufler 2018) has found that skills are only implicitly ingrained in the curriculum. A paper exploring skills and foreign policy courses in Germany identified that despite acknowledging the skills issues, 'alternative innovative teaching methods, such as the drafting of policy papers, seem only rarely to have found their way into curricula' (Nieman and Heister 2010). Research has shown that the politics/IR curricula in the UK provides students with a range of transferable skills that they will find of great use as they move towards employment, the discipline is poor in highlighting this: 'if we don't tell students what we are teaching them, then they won't realise that they have gained a whole range of skills through their study of politics' (see Clark and Martin 2016). An obvious way to ensure all students engage with the skill development aspect of this agenda is to embed and assess the skills via the choice of assessment (Curtis 2013) and across the curricula (Adriaensen et al 2019). Yet it is clear that essay writing is the most common form of assessment (Deardorff et al 2009; Blair and McGinty 2012) and whilst it is clear essay writing allows students to develop a range of transferable skills, the need to ensure students can demonstrate the full range of skills demands a broader range of assessment tasks. There is also a need to ensure students make the link between the skills they develop in research intensive universities like Leeds and the skills required by employers (Biswas \& Haufler (2018). This can be seen as research-led employability (see Lightfoot 2015). Therefore given the low usage rates of "authentic assessments" in Politics and IR, the need for so-called show and tell pieces is still there, in part to inform practice across the sector but also to form an evidence base for the discipline that will then feed into broader discussions about assessment at the subject level. As such this paper sets out to reflect on the use of the same assessment over different iterations of the same module to provide a case study of practice. 


\section{POLICY BRIEFS AS INNOVATIVE ASSESSMENT IN POLITICAL SCIENCE AND IR}

A policy brief is a 'concise summary of a particular issue, the policy options to deal with it, and some recommendations on the best option. It is aimed at government policymakers and others who are interested in formulating or influencing policy' (FAO nd). As a result, the policy brief is a commonly used tool in a range of jobs related to politics and IR, such as civil servant, lobbyist or NGO. It is therefore perhaps surprising that there use as an assessment tool in politics/IR courses remains underutilised (see Boys and Keating 2009; Pennock 2011; Trueb 2013; Biswas \& Paczynska 2014; McMillan 2014; Chagas-Bastos and Burges 2018 for exceptions). The literature shows that the assessment method encourages students to develop 'real world' skills (very few jobs require the employee to regularly write 3000 words, most tend to need short, persuasive briefs), whilst also demonstrating academic knowledge (Moody and Bobic 2011). Assigning students policy briefs and policy memos gives them the opportunity to practice the type of writing they will perform both inside and outside of academia while still developing critical thinking skills and an understanding of the political world. The key elements of synthesis and analysis are honed via the use of policy briefs according to Penncock (2011). Feedback from alumni highlights that they would have welcomed the opportunity to engage with shorter pieces of writing that were more akin to the tasks they had to produce in their graduate jobs and chimes with feedback I have received and is discussed in the literature (Raile et al 2017).

In particular, a key element of getting a job in either the UK or EU Civil Service would be the case study or written Policy Recommendation Exercise in the assessment centre. The mock test for the EU process shows the benefit of using policy briefs in foreign policy courses as the 90- minute test makes the candidate assume the role of desk officer at DG Enlargement within the Unit responsible for the Balkan Region. The task involves reading documents provided to identify the key issues and potential solutions to a specific situation in the Balkans to assess the following competencies: Analysis and problem solving, Communicating (drafting skills), Delivering quality \& results and Prioritising \& Organising (EPSO, nd). Exposing students to the challenges of short, focused writing (albeit without the strict time pressure), highlighting the skill sets involved and explaining where they are likely to utilise these skills post -graduation are explicitly found in an assessment task such as the policy brief. Therefore, to ensure graduates in political science or IR are able to compete in the job market the discipline needs to provide them with the skills to do so as an integrated part of their program. It is one thing not to get a job because other people were better qualified; it is quite another thing not to get the job because you did not know the rules of the game, which has been defined as empowerment based employability skills (see Lee at al 2014) of which "authentic" assessments are one way in which students can be empowered.

\section{MODULE CONTEXT: HOW IS THE COURSE STRUCTURED?}

The context is a final year undergraduate optional module that has been running since 2014 at the University of Leeds. The specific nature of the policy brief lent itself to use in this particular course given the topic-that of the politics of foreign aid. Foreign aid is clearly linked to foreign policy and the use of policy briefs as a tool of communication in foreign affairs ministries is well documented. Biswas and Paczynska (2014) utilised policy briefs in the classroom based on their experiences as Franklin Fellows at the United States Department of State. The aid context is, furthermore, interesting because short, focused pieces of writing like policy briefs are widely used by NGOs, think-tanks and government departments. It was therefore clear that many of the students on this specific module would go into careers, in which the ability to write a policy brief would be a useful skill.

Class sizes range from $75-90$ students over the past 5 years. Students tend to be politics/IR/development studies students (including joint honours). As an elective module, students can choose this module with no prerequisite courses. It is also open to Erasmus/Year Abroad students. 
Whilst this on the surface presents an opportunity to offer a longitudinal analysis of performance over five years, the nature of developing a new module is that refinements and changes are made in response to both student feedback and the external environment. As such this article offers a case study of the evolution of an assessment type in a final year module, student views of the assessment task and broader issues associated with the nature of this assessment task.

The literature above and an interest in employability/skills within the political science curriculum was motivation behind the choice of assessment task in the first place (see Lightfoot 2015). Therefore, when designing a module on the Politics of Aid I wanted to a: choose a form of assessment that tested new skills and b: make the skill development process/ skills acquired in module more explicit (with a coincidental link to graduate outcomes agenda in the UK). I had also been talking to graduates and undertook some research with them that highlighted the skills they obtained from their degree and the skills they used in their current employment and the overlaps or not between them. An underlying theme of this research was that many alumni wished they had been able to undertake assessment tasks similar to those they conducted in their employment. I was also impressed by the work of students at another UK university, where policy briefs were used in assessment.

In order to prepare the students for the assessment and in an attempt to reduce student 'angst' (Chagas-Bastos and Burges 2018) a 5 page document outlines the nature of the task and why I ask them to do it, key elements that must be in the brief, expectations of what topics might be covered and general notes on report writing. A list of aid-related policy briefs from thinks tanks (Overseas Development Institute, Centre for Global Development), NGOs (Save the Children) and government (UK parliament briefings) are provided to the students and these are discussed in the seminars. The purpose of the assessment is also explained, especially the skills/employability angle. This chimes with the excellent advice provided by Chagas-Bastos and Burges (2018). Ensuring students are clear as to the nature of the task and how it will be assessed are key features the literature highlight for success of the task. An aspect I found particularly helpful was stressing the similarities and differences between essays and policy briefs, particularly as the format and structure of the policy brief were the main concerns for students. Chagas-Bastos and Burges (2018) highlight an interesting aspect of terminology: whether you call something a briefing note or a policy brief or a policy paper could impact upon the nature of the task. So, for example there is a clear difference between providing background information on a country or topic, setting out and potentially offering a range of options for action on a topic and writing as advocacy (I return to this issue later).

The assessment of the course as well as the delivery have evolved over time: in part due to design and in part due to workload. The module has evolved from a single academic delivering all aspects of the module to a team of 3-4 academics. Whilst a major driver for this change was workload, the teambased approach actually allows students to see the topic from different research backgrounds and traditions thus ensuring a more rounded approach to the topic, i.e. bringing in someone who utilises more quantitative methods in their research on aid or specific country experts.

The final policy briefs address the question: In the form of a policy brief, provide a critical evaluation of the development aid policy of any one DAC member. In keeping with the nature of the assessment students must decide the country, the key time frame and therefore the context of the aid policy of their chosen state. To do the assessment requires excellent research skills and the fact that students have a choice of 30 states helps motivation. The module introduces students to key concepts, issues and debates relating to country level aid allocation, it also aims to introduce students to the political, economic and moral rationales of why international donors provide foreign aid. Alongside the "foreign policy" drivers it examines the role of NGOs and political parties in influencing decisions about aid levels. The assessment task asks students to examine the aid decisions of specific countries to meet the following learning outcomes: 
- Critically examine the key concepts and definitions of aid;

- Analyse trends in and global levels of aid;

- Analyse the political, commercial, and moral rationales for foreign aid;

- Understand the links between aid and non-aid policies.

The policy brief allows the students to capture these outcomes within the specific context of their chosen state and demonstrate research-led teaching.

\section{Module and assessment evolution}

The assessment was amended after 2 iterations of the module. The initial assessment was the policy brief (30\%) and a seen exam (70\%). After running the module for 3 years it was clear that to write a good 1500- word policy brief needed more planning and drafting than longer assessments and that the $30 \%$ weighting undervalued the time needed. The revision of the assessment task coincided with a university wide focus on assessment and feedback. I had a view that that there were too many assessment points in a student (and markers) lifecycle. So, the move to drop the exam fitted that agenda. In addition, the current framework within which all modules operate in Leeds Expectations for Assessment and Feedback. This asks that 'assessment should be sufficiently authentic to prepare students for [graduate] employment, further study or research'. It goes on to ask whether 'towards the end of the programme, do at least some of your school's assessments resemble the sort of activities that your graduates might encounter when in employment or embarking on further study?' The two aspects came together over at least 2 years. First, I realised that students focused considerable energy on the policy brief, yet it was worth only $30 \%$ of the final mark. Plus I worried that the exam offered assessment for the sake of assessment and I also felt the exam risked repeating topics that were already covered in the policy brief and so from 2017-18 the exam was removed and the assessment task became a portfolio of draft policy brief, unassessed presentation and 1500 word policy brief.

The draft was formalised into the assessment to a: ensure students realised the link between drafts and the final submission and $b$ : provide specific support on an unfamiliar assessment type. Interestingly, in line with Chagos the presentation was designed to support students prepare for their policy brief by allowing students to practice presenting key points on specific case studies. Linked to this was another innovation within the module over time to include a much more focused reading list for seminars whereby students read key articles to provide the foundations of knowledge. These articles then provide a generic check list of factors that students will need in analysing their chosen country of study.

Working out how effective this assessment method was is tricky. This is perhaps the main weakness of this type of case study. The fact that data was only captured via the usual student education mechanisms at Leeds plus the module evolvement over time means that I cannot hold factors as control. Student feedback on the module was generally favourable with unprompted qualitative comments noting the policy brief assessment in generally positive terms. This article draws upon module reviews, external examiner comments and solicited feedback from 3 different graduates from the module. To fully utilise the data is tricky due to the changing nature of the module.

There was a specific issue related to the draft submission that I will focus on separately. The external examiner in 2017 noted that 'An interesting assignment and one which has been tackled well by the students. A good spread of marks, with the lowest mark of $52 \%$ suggesting that students have engaged really well and received strong guidance on tackling the assessment'. What is clear is that the top end 
work by students captured the essence of the literature on this assessment task i.e. it highlighted the ability to synthesise and analyse a wide range of sources and arguments in a concise and readable form. As Doyle argues that the language used in policy briefs should strive for maximum readability, with a 'capsule version of the key points and considerations about an issue' (Doyle 2017). Targeting knowledge in a briefing note is fundamental, seeking to distil 'complex information into a short, wellstructured document' (Doyle 2017). Chagas-Bastos and Burges argue that the 'central challenge of writing a good briefing note is thus to present complex, detailed information in an ordered, coherent manner that is easily read and can be 'absorbed on the fly' by busy decision-makers rushing between important meetings'.

The end result was that a large number of student students could produce work of a very high quality (so much so that 3 students presented the findings of their policy brief to a conference on UK aid attended by think-tanks and MPs). The levels of synthesis and analysis are generally much higher than those produced in longer traditional essay formats. I have also been struck by the way the task mirrors the expectations of the Fast Stream "brief" in the assessment centre. In particular, the criteria state 'there is no right answer; a good case can be made for the scenarios. The important thing is how you support your decision, using the facts provided, and how you express this in writing' (Faststream 2019). In the field of politics and IR helping students understand that there are no right answers and that their job as researchers is to make sense of the arguments is also aided by the concise nature of the task. It is unclear how many students made the explicit link between the course and assignment and their "employability" during the module although there are a few qualitative comments to suggest that some did. Feedback from graduates though suggested that for many having experience of writing policy briefs was helpful in either acquiring employment or carrying out tasks in employment, especially those who went into public administration roles.

\section{PEDAGOGIC OBSERVATIONS AND REFLECTIONS}

Chagas-Bastos and Burges (2018) found that to produce a good policy brief 'it is consequently necessary to continuously emphasize the importance of revising and editing, actively encouraging students to deliberately think in terms of drafts'. Their article also highlights a key finding from my own experience: students need to make decisions about 'what matters' as 'writing a briefing note involves hard choices about what to include and what to exclude'. The need to start drafting early to ensure students really understand the topic is therefore been made explicit by the inclusion of a formal draft deadline at least 2 months before the final submission. Student feedback highlights that deciding what matters is tricky: 'as a student, the trap I fell into was treating the task too much like a literature review. The policy brief should use the literature to justify why (and what) policy action is required'. This confirms the literature that argues that 'synthesis and evaluation are particularly critical since-given the length of the paper-students must weave together arguments and make judgments on the best evidence that can be harnessed to support the thesis as well as make assessments and recommendations in those papers with a policy connection' (McMillan 2014).

However, what is clear from the five iterations of the module is that the need to act on feedback is not always clear to students. To counter this and the fact that not all students will have undertaken a similar task has meant that formative feedback has been built into the module from day one. There is an attempt to ensure this feedback is as individual as possible with 121 feedback on drafts an opportunity for all students in the first iterations of the module. Now, this became a formal element of the assessment, which has raised a number of issues.

The first is the tension between generic versus tailored support. The literature stresses the need for feedback to be more personal (Williams and Smith 2017) so each student has the opportunity to obtain personal feedforward on their draft. In that sense the module tried to mirror the research process 
(draft, comment and re-draft). However, it was clear from a minority of students that this was not clear them. The particular issues were the fact that the draft deadline clashed with the final stages of the final year project and as such students tended to prioritize the final year project. Clearly managing multiple deadlines is an essential skill in most forms of employment as is prioritizing tasks but is there enough space in the curriculum to explain this aspect of skills development? (see Adriaensen et al 2019).

In addition, more than one student criticised the deadline because it meant they would not have time to "finish" their draft. The criticism ran along the lines of "if I had more time my draft would be better" with some students explicitly criticising the amount of time they had to re-draft after the feedback. Again, this prompted reflection as to whether the benefits of re-drafting are made explicit to students? This process is now given prominence in the module handbook and during lectures. Two examples are provided to show the need for re-drafting-a picture of the American constitution showing the change on the draft from 'We hold these truths to be sacred and undeniable' to 'We hold these truths to be self-evident' and the example of WD-40 a product named after the 40th attempt to create a water displacement solution.

The academic literature on draft-re draft for undergraduates highlights some issues that were not considered, such as how students handle feedback or how the nature of the feedback should vary by student i.e. stronger students get suggestions for improvement whilst weaker students get commands 'you need to' (see Court 2012). This strongly suggests that academic staff should more explicity "teach" students how to use feedback. Re-reading Williams and Smith's excellent (2016) article alongside Blair et al (2012) highlights what students feel about feedback and what type of feedback they want. Feedback also has a very human reaction in students and this informs how they use feedback (Shields 2015; Pitt \& Norton 2017; Green, 2019). In many ways as academics we must remember feedback on university assessments is a human to human communication no different to the ones we encounter (and often complain about) in peer review (see Curtin et al, 2018). Factoring this research into the practice on the module and using mechanism to develop students feedback literacy (Carless and Bould 2018) may help students understand the benefits of draft feedback.

It was also clear that students who did not "get" the assessment tended to avoid seeking advice by either not seeing academic staff and/or not submitting a draft. Simon Usherwood has noted a similar trend in his assessment task. He states that there was a 'cluster of students who simply didn't 'get' the assessment - a reflective essay - and thus came out with poor marks. This time, I had only a couple of students in that situation, and they appeared (from my records) to have neither attended most of the classes nor used the opportunity for a conversation' (Usherwood 2019). We tried to tackle this by making the submission of the draft an element of the portfolio but it is still an area of concern.

Another issue that I had not paid attention to was that the reduction in assessment tasks actually increased anxiety with some students. Some students felt more anxious, as the one-strike nature of the assessment meant also higher stakes. The "innovative" nature of the assessment adds to this anxiety due to the unfamiliarity to the student. One student noted that 'I would advise against it being the sole assessment of a module due to the lack of familiarity most students have with policy briefs'. This therefore provides evidence that attempts to introduce authentic assessment tasks into politics/IR curricula need to be done so at a programme level so as to ensure proper scaffolding of support for students by mapping assessment tasks and skill development across the programme. 


\section{THE WAY FORWARD: HOW TO FURTHER IMPROVE THE USE OF POLICY BRIEFS FOR ASSESSMENT?}

Reflecting on the module delivery over the past 5 years the benefits of the policy brief as an assessment task are clear to me as a teacher as l'll discuss later. The assessment task does prompt some deeper questions. The first is how "real-world" does the task need to be? Can classroom assessment ever be real? This is an interesting challenge given that innovative tools can very often be presented in very traditionally ways. This module is no different with an explicit requirement to reference academic texts throughout the policy brief. One solution would be to mirror the type of tasks set in assessment centres. This could be in the form of a traditional take home assessment or even as a type of open book, seen exam. One colleague brings practitioners in to advise on the question and "mark" assignments. This provides an authentic element and reinforces the research element but it might be unrealistic. Practitioners attend university to present a policy brief from their work place and share tips and trips maybe half-way through the course?

Does the assessment need specific assessment criteria? Can you assess academic skills such as use of literature without references? It is clear that policy briefs exist for different purposes so does the task need a scenario. This would also help deal with student feedback such as a lack of clarity as to what 'what the aim and content of a policy brief needs to be'. One option might be to provide a scenario: You are writing this for a senior member of the EEAS as a civil servant to provide key facts on EU peace keeping in Mali? You are working for a human rights NGO and you wish to change EU policy on...'. There is an opportunity here to learn from the literature in problem-based learning which shows that different type of assignments can be used to address different levels of learning (Schmidt \& Moust 2010).

Clearly defining the audience appears key to make the assessment more authentic and this is a change that I will make in the future. Within this framework students might be able to experiment and choose their audience (an NGO or for a brief in a ministry) which coupled with a reflective element would focus again on both skill development and employability. The fact that the policy brief sits within a portfolio would allow a reflective task to sit alongside the more formal policy brief relatively easily. Other possibilities include elements of group work could be introduced which have different students working on the same country, and then ask them to present; all students could then judge which brief was most persuasive and one could discuss why.

Student comments highlight the fact that in their use of policy briefs in the workplace a graduate found they were utilised more for persuasion. The point about taking a position is very clear: 'I would suggest it's important to remember that a policy brief is not unbiased- they are written by organisations which often have their own political agenda and are using the brief to influence others'. Having an ability to understand the organisation you work for and its aims and values is an under-appreciated graduate skill. The aim is not to teach organisational culture but to make politics and IR graduates more aware of the fact that these differences exist-in many ways it is a form of commercial awareness. Personally this would raise some issues around my capabilities as a marker. Am I assessing persuasive writing or advocacy skills? These are not insurmountable problems (similar to assessing presentations) and need to be tackled to ensure students understand.

\section{CONCLUSIONS}

This paper has made a case for the use of policy briefs on Politics/IR modules. It also argues that given their use in assessment centres for jobs within the EU it has a special resonance for European Studies course, especially those with a foreign policy focus. It argues that shorter policy brief style pieces should fit well into the political science/IR curriculum as the skills they encourage are ones we seek from our students plus as McMillan (2014) points out 'few fields (of employment) require papers of 10 
pages or more. Instead, shorter memos, letters, briefs, and reports are expected tasks'. Student feedback noted that 'a policy brief provides you with a set of transferrable written communication skills which can be applied when working. [the skills of] 'being succinct and informative I found to be often overlooked and under nurtured whilst studying for a politics-related bachelor of arts'. Policy briefs prepare students for authentic employment tasks whilst allowing them to demonstrate critical thinking, synthesis, analysis and concise writing skills. This article concurs with Chagas-Bastos and Burges (2018) in that the briefing note serves multiple purposes; standard testing of knowledge and skills; builds student communication skills by teaching them a new format; format can encourage deep synthesised learning. The combination with an explicit research focus also helps connect employability (often an add on) to the core curriculum-the research-led employability argument. One specific angle that is important for Politics/IR is that all students on a module can engage with an employabilityfocused assessment not just the few who undertake a placement. As Chagas-Bastos and Burges (2018) show this method can be utilised with modules with $100+$ students as well as smaller cohorts. In addition, the coupling of skills and subject knowledge is key to student engagement. Whilst it is still unclear whether all students explicitly get this or identify which key skills they have developed and notwithstanding the improvements suggested above, the use of a policy brief has been a positive one for me. Given the topics covered in most foreign policy courses lend themselves to this type of assessment and given that it combines "authenticity" with academic rigour makes me wonder why the method is not more widely utilised in Politics and IR courses than it is.

\section{ACKNOWLEDGEMENTS}

A version of this paper was presented at PSA/BISA 11th Annual Learning and Teaching Conference 2018 at the University Of Leeds. I would like to thank Heidi Maurer, Heather Savigny, Patrick Bijsmans and Friedrich Plank and the reviewer for their helpful comments on earlier drafts. The end paper is much improved as a result of their feedback.

\section{AUTHOR DETAILS}

Professor Simon Lightfoot, School of Politics and International Studies, University of Leeds, Leeds LS2 9JT, United Kingdom [s.j.lightfoot@leeds.ac.uk].

\section{REFERENCES}

Adriaensen, J., P. Bijsmans and A. Groen (2019). 'Monitoring Generic Skills Development in a Bachelor European Studies', Journal of Contemporary European Research 15(1): 110-127. https://doi.org/10.30950/jcer.v15i1.1018.

Blair, A. and S. McGinty (2012). 'Developing Assessment Practices in Politics', in C. Gormley-Heenan and S.Lightfoot (eds.), Teaching Politics and IR, Palgrave: Basingstoke: 105-122.

Blair, A. (2015). 'Performance Assessment in Europe' in Ishiyama, John, William J. Miller and Eszter Simon. Handbook on Teaching and Learning in Political Science and International Relations. Cheltenham, UK: Edward Elgar: 85-94.

Boys, J. D. and M. Keating (2009). 'The Policy Brief: Building Practical and Academic Skills in International Relations and Political Science', Politics, 29 (3): 201-208. https://doi.org/10.1111\%2Fj.1467-9256.2009.01356.x.

Biswas, B and A. Paczynska (2014). 'Teaching Theory, Writing Policy: Integrating Lessons from Foggy Bottom into the Classroom', PS: Political Science and Politics 48 (1); 157-61. https://doi.org/10.1017/S104909651400170X. 
Biswas, B. and V. Haufler (2018). 'What Can I Do with This Class? Building Employment-Related Skills in International Relations Courses', Journal of Political Science Education. https://doi.org/10.1080/15512169.2018.1515634.

Broms, R. and de J. Fine Licht (2019). 'Preparing political science students for a non-academic career: Experiences from a novel course module'. Politics. https://doi.org/10.1177/0263395719828651.

Carless, D and D. Boud (2018). 'The development of student feedback literacy: enabling uptake of feedback', Assessment \& Evaluation in Higher Education, 43 (8): 1315-1325. https://doi.org/10.1080/02602938.2018.1463354.

Clark, A. and T. Martin (2016). 'An audit of transferable skills teaching in UK politics departments'. European Political Science, 15(3): 389-403. https://doi.org/10.1057/eps.2015.94.

Chagas-Bastos, F. H. and S. Burges (2018). 'The "Briefing Note" as a Pedagogical Tool for Teaching Politics and International Relations'. Journal of Political Science Education 15 (2): 237-246. https://doi.org/10.1080/15512169.2018.1472001.

Court, Krista (2012) 'The use of tutor feedback on draft essays: exploring the potential to develop students' academic writing and subject knowledge'. Journal of Further and Higher Education, 38 (3): 327-45.

https://doi.org/10.1080/0309877X.2012.706806.

Curtin, P. A., J. Russial and A. Tefertiller (2017). 'Reviewers' perceptions of the peer review process in journalism and mass communication'. Journalism \& Mass Communication Quarterly, 95(1): 278-299. https://doi.org/10.1177\%2F1077699017736031.

Deardorff, M, K. Hamann and J.Ishiyama, eds. (2009). Assessment in Political Science. Washington, DC: American Political Science Association.

Doyle, Susan. 2017. Writing for Government and the Public Sector (ENGL302). University of Victoria. https://web.uvic.ca/ sdoyle/E302/Notes/WritingBriefingNotes.html.

EPSO (nd) Mock case study. http://europa.eu/epso/doc/mock_casestudy_en.pdf.

FAO (nd) How to write policy briefs, http://www.fao.org/3/i2195e/i2195e03.pdf.

Fast Stream (2018) Fast Stream Assessment Centre (FSAC) Guide 2018-2019,

https://www.faststream.gov.uk/media/1273/fsac-guide-2018-fv.pdf.

Green, Simon (2019). 'What students don't make of feedback in higher education: An illustrative study, Journal of English for Academic Purposes 38: 83-94. https://doi.org/10.1016/j.jeap.2019.01.010.

Gulikers, J., T. Bastiaens and P. Kirschner (2004). 'A five-dimensional framework for authentic assessment'. Educational Technology Research and Development, 52 (3): 67-85. https://doi.org/10.1007/BF02504676.

Lee, D., E. Foster and H. Snaith (2014). 'Implementing the Employability Agenda: A Critical Review of Curriculum Developments in Political Science and International Relations in English Universities', Politics 36 (1): 95-111. https://doi.org/10.1111\%2F1467-9256.12061.

Lightfoot, S. (2015). 'Promoting employability and jobs skills via the political science curriculum', in John Ishiyama, William J. Miller, and Eszter Simon (eds.): Handbook on Teaching and Learning in Political Science and International Relations. Cheltenham: Edward Elgar Publishing: 144-154.

Lincoln, T and R. Casidy (2018). 'Authentic assessment in business education: its effects on student satisfaction and promoting behaviour', Studies in Higher Education, 43 (3): 401-415. https://doi.org/10.1080/03075079.2016.1165659.

Maurer, H. and J. Mawdsley (2013). 'Students \& skills, employability and the teaching of European studies: challenges and opportunities', European Political Science 13: 32-42. https://doi.org/10.1057/eps.2013.34. 
McMillan, Samuel (2014). 'Bravo for Brevity: Using Short Paper Assignments in International Relations Classes', International Studies Perspectives 15 (1): 109 -20. https://doi.org/10.1111/insp.12003.

Niemann, A. and S. Heister (2010). 'Scientific Political Consulting and University Education in Germany: Demand and Supply Patterns in the Context of the Bologna Process', European Political Science, 9 (3): 398-416.

https://doi.org/10.1057/eps.2010.17.

Pennock, Andrew (2011). 'The Case for Using Policy Writing in Undergraduate Political Science Courses', PS: Political Science \& Politics, 44 (1): 141-146. https://doi.org/10.1017/S1049096510002040.

Pitt, E and L. Norton (2017). 'Now that's the feedback I want!' Students' reactions to feedback on graded work and what they do with it', Assessment \& Evaluation in Higher Education, 42 (4): 499-516.

https://doi.org/10.1080/02602938.2016.1142500.

Raile, E., E. Shanahan, M. Wallner and L. Young (2017). 'Using Alumni Views to Connect the Past, Present, and Future in Political Science'. PS: Political Science \& Politics, 50(3): 837-841. https://doi.org/10.1017/S1049096517000695

Robinson, Andrew (2013). 'The Workplace Relevance of the Liberal Arts Political Science BA and How It Might Be Enhanced: Reflections on an Exploratory Survey of the NGO Sector', PS: Political Science \& Politics, 46: 147-153.

https://doi.org/10.1017/S1049096512001308

Schmidt, H. and J. Moust (2010). 'Designing problems'. In: H. Van Berkel, A. Scherpbier, H. Hillen, \& C. Van der Vleuten (Eds.), Lessons from problem-based learning Oxford: Oxford University Press: 31-45.

Trueb, Bettina (2013). 'Teaching Students to Write for “Real Life”: Policy Paper Writing in the Classroom'. PS: Political Science \& Politics 46 (1): 137-141. https://doi.org/10.1017/\$1049096512001333.

Usherwood, Simon (2019). 'From formative feedback to assessment outcomes', https://activelearningps.com/page/4/.

Villarroel, V, S. Bloxham, D. Bruna, C. Bruna and C. Herrera-Seda (2018). 'Authentic assessment: creating a blueprint for course design', Assessment \& Evaluation in Higher Education, 43 (5): 840-854. https://doi.org/10.1080/02602938.2017.1412396.

Williams, H. and D. Smith (2017). ‘Feedback: critiquing practice, moving forward', European Political Science 16: 159. https://doi.org/10.1057/eps.2015.99. 